Case Study

\title{
The effect of a powered ankle foot orthosis on walking in a stroke subject: a case study
}

\author{
Ali Pourghasem, $\mathrm{PhD}^{1)^{*}}$, Ismail Ebrahimi Takamjani, $\mathrm{PhD}^{2)}$, \\ Mohammad Taghi Karimi, PhD ${ }^{3,4)}$, Mohammad Kamali, $\mathrm{PhD}^{5}$, \\ MOHAMmad JANNESARI, MSc ${ }^{6}$, IMAN SALAFIAN, $\mathrm{MSc}^{7}$ ) \\ 1) Department of Orthotics and Prosthetics, Faculty of Rehabilitation Sciences, Iran University of \\ Medical Sciences, School of Rehabilitation Sciences: Nezam St. Shah Nazari Ave., Madar Sq. \\ Mirdamad Biv. Tehran 4391-15875, Iran \\ 2) Department of Physiotherapy, Iran University of Medical Sciences, Iran \\ 3) Musculoskeletal Research Center, Isfahan University of Medical Sciences, Iran \\ 4) Rehabilitation Sciences Research Center, Shiraz University of Medical Sciences, Iran \\ 5) Rehabilitation Research Center, Iran University of Medical Sciences, Iran \\ 6) Department of Mechanical Engineering, Isfahan University of Technology, Iran \\ 7) Department of Mechanical and Material Engineering, University of Nebraska-Lincoln, USA
}

\begin{abstract}
Purpose] Standing and walking are impaired in stroke patients. Therefore, assisted devices are required to restore their walking abilities. The ankle foot orthosis with an external powered source is a new type of orthosis. The aim of this study was to evaluate the performance of a powered ankle foot orthosis compared with unpowered orthoses in a stroke patient. [Subjects and Methods] A single stroke subject participated in this study. The subject was fitted with three types of ankle foot orthosis (powered, posterior leg spring, and carbon ankle foot orthoses). He was asked to walk with and without the three types of orthoses, and kinetic and kinematic parameters were measured. [Results] The results of the study showed that the moments applied on the ankle, knee, and hip joints increased while walking with the powered ankle foot orthosis. [Conclusion] As the powered ankle foot orthosis influences the moments of the ankle, knee, and hip joints, it can increase the standing and walking abilities of stroke patients more than other available orthoses. Therefore, it is recommended to be used in rehabilitation programs for stroke patients.

Key words: Stroke, Walking, External powered orthosis
\end{abstract}

(This article was submitted May 22, 2016, and was accepted Jul. 19, 2016)

\section{INTRODUCTION}

Stroke is the second highest cause of disability and death worldwide ${ }^{1,2)}$. Because of muscle weakness, spasticity, impaired sensorimotor control, or loss of cognitive functions, walking ability after stroke is often disturbed ${ }^{3,4)}$. It has been shown that stroke patients have a decreased walking speed, asymmetric gait pattern, muscular weakness, abnormal movement strategies, and spasticity ${ }^{3,5)}$. Due to the abovementioned gait abnormalities; these patients have a high risk of falling and high energy consumption during walking ${ }^{4}$. At present, motion analysis systems has being used to determine the abnormalities associated with stroke. For example, the moments applied to the joints, which are determined by inverse dynamics, are used as indirect indicators of the weakness of muscles and joint contracture ${ }^{6}$, and it is known that reduced walking speed not only increases energy consumption during walking but also influences the forces applied to the foot. Gait abnormalities are determined based on the kinematics of the joints calculated by inverse kinematics ${ }^{6,7)}$. Stroke patients use assistive devices to improve

*Corresponding author. Ali Pourghasem (E-mail: poorghasem@rehab.mui.ac.ir)

(C2016 The Society of Physical Therapy Science. Published by IPEC Inc.

This is an open-access article distributed under the terms of the Creative Commons Attribution Non-Commercial No Derivatives (by-nc-nd) License $<$ http://creativecommons.org/licenses/by-nc-nd/4.0/>. 
their abilities to stand and walk. Use of some assistive devices, such as the ankle foot orthosis (AFO) or an external powered $\mathrm{AFO}$, has been recommended for these patients ${ }^{8-10)}$. However, the effect of AFOs on walking in these patients depends on the structure of the orthoses and their ankle mechanisms ${ }^{8,9,11)}$. Gok et al. showed that the gait of hemiplegic subjects is improved more by a metal orthosis than a plastic AFO due to the better stabilization it provides during the stance phase ${ }^{12}$ ). In contrast, De Wit et al. showed that although the effect of an AFO on the walking abilities of stroke patients was statistically significant, the difference was too small to be clinically relevant ${ }^{10}$.

The main problems of the stroke patients during walking is a significant decrease in ankle joint plantar flexion power compared with that in normal subjects ${ }^{5}$. Various attempts have been made to restore plantar flexion moment in stroke patients by using an external powered orthosis ${ }^{10,13-21)}$. The idea of incorporating an active ankle mechanism in the design of AFOs has been around since 1980. In the first design of this kind of orthosis, hydraulic and pneumatic actuators were used to power the ankle joint. Up to now, various approaches have been used to restore the power of the ankle joint, including a series elastic actuator (SEA), magneto rheological fluid, passive pneumatic element, frictional clutch, oil damper, artificial pneumatic muscle and shape memory alloys ${ }^{18)}$. Use of an SEA is more advantageous. It has a low controlled impedance, good control bandwidth, shock tolerance, low friction, and high force fidelity. However, in most studies, walking and standing ability have not been evaluated in patients with ankle impairment (stroke) wearing this kind of external powered orthosis. Furthermore, normal subjects have been used in most studies ${ }^{22}$.

Therefore, the aim of this study was to introduce a new type of AFO designed for stroke subjects based on the protocol used by Pratt and Blay et al. ${ }^{23)}$ to evaluate the kinetic and kinematic performance of a stroke patient walking while wearing this orthosis, and to compare the results with those of other orthoses. It should be emphasized that there are actually two reflexes that can be seen in tendon and muscles fibers, tonus and jerk responses, as discussed by Pratt and Blay et al. The tonus response occurs slowly and depends on the applied load. The new design of the active AFO is based on tonus behavior. In the new design, the moment of plantar flexion of the ankle joint to resist external moment and push the subjects forward is not constant and can be changed according to the external applied moment and ankle angle. In the present study, this concept was used to design an orthosis, and the new orthosis was tested on a subject with stroke rather than a normal subject.

\section{SUBJECTS AND METHODS}

A poststroke patient participated in this study at 11 months after stroke. The weight, age and height of the subject were $83 \mathrm{~kg}$, 45 years, and $178 \mathrm{~cm}$, respectively. Ethical approval was obtained from the Ethical Committee of Isfahan University of Medical Sciences. A consent form was signed by the subject before data collection. The main inclusion criteria in selection of the subject in this study were as follows:

1) First stroke

2) At least 6 months post stroke

3) Able to stand for at least one minute without any assistive devices

4) Able to walk for at least 10 meters

Moreover, the subject was asked to not use any medicine that could influence his stability at least 10 hours before data collection.

External powered orthosis: A new type of external powered orthosis was designed that consisted of a polypropylene AFO with a hinged ankle joint, two on/off switches, upper level (master) controllers, and an SEA. The SEA included a coupling, metal plates, four compression springs, eight bushings, one ball screw, one ball nut, and four guide rails (Fig. 1). The compression springs were used in this design to minimize the effect of backlash and to isolate the motor from shock loads and torque ripple. The ball screw and ball nut were used to convert the rotary motion of the motor into linear motion. The SEA is able to generate enough force to move the ankle in response to the control signal of the motor. The SEA was a of a $100 \mathrm{~W}$ AC servomotor with a maximum speed of 5,000 rpm (XML-SA01A, LS Mecapion). An encoder attached to the motor controls the operating conditions of the motor.

The master controllers (PCI-1710 and PCI-1723, Advantech) used in the developed AFO detect the velocity and duration of each gait phase based on the output signals from the on/off switches during walking (Fig. 1). Furthermore, they generate a motor drive velocity command. An industrial motor drive (XDL-L740A001, LS Mecapion) was used to regulate motor voltage with embedded velocity control. In order to control the system, the gait cycle was divided into three states, each with a separate functional objective. In the first control state, which lasted from heel strike to midstance, the SEA mechanism was used to increase the impedance at the ankle joint. From midstance until toe off, the impedance of the AFO decreased (second state). The third control state was during the swing phase, and it was used to maintain toe clearance. Communication between actuators, foot switches, and a processing unit (laptop) was accomplished by using a data acquisition unit (DAQ).

A Qualisys motion analysis system with 7 high-speed cameras and a Kistler force plate was used to record the motion of the body and force applied to the leg during walking. The locations of markers were recorded with the Qualisys Track Manager software. Subject's lower extremities and trunk were reconstructed by visual 3D software produced by C-motion Inc. This software was also used for calculation of the changes in the angles of the trunk, hip, pelvis, knee, and ankle joints during walking. It should be emphasized that the data from the force plate and cameras were collected at a frequency of $120 \mathrm{~Hz}$. The moments applied to the joints were determined based on the inverse dynamics approach by use of force and center of 


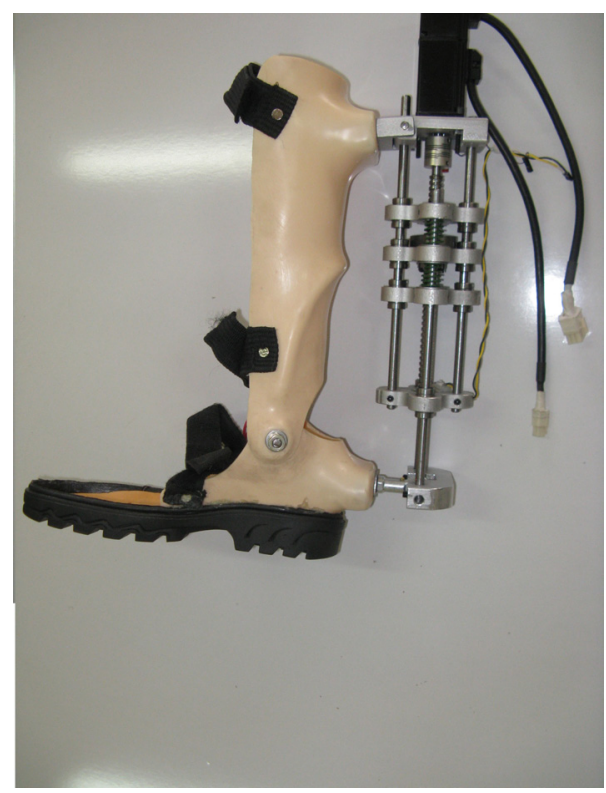

Fig. 1. External powered orthosis

Table 1. The gait parameters of the stroke subject during walking without and with three types of orthosis

\begin{tabular}{llcccccc}
\hline $\begin{array}{l}\text { Orthosis } \\
\text { type }\end{array}$ & Test condition & $\begin{array}{c}\text { Velocity } \\
(\mathrm{m} / \mathrm{min})\end{array}$ & Stride $(\mathrm{m})$ & $\begin{array}{c}\text { Cadence } \\
(\text { steps } / \mathrm{min})\end{array}$ & Force X $(\mathrm{N})$ & Force Y $(\mathrm{N})$ & Force Z $(\mathrm{N})$ \\
\hline Powered & Without orthosis & $9.72( \pm 2.85)$ & $0.46( \pm 0.09)$ & $45.2( \pm 6.28)$ & $33.64( \pm 1.77)$ & $23.1( \pm 4.08)$ & $587.8( \pm 16.02)$ \\
AFO & With orthosis & $8.31( \pm 0.57)$ & $0.67( \pm 0.039)$ & $24.76( \pm 1.11)$ & $21.65( \pm 14.51)$ & $27.5( \pm 9.94)$ & $774.66( \pm 9.36)$ \\
PLS & Without orthosis & $9.72( \pm 2.85)$ & $0.46( \pm 0.09)$ & $45.2( \pm 6.28)$ & $33.64( \pm 1.77)$ & $23.1( \pm 4.08)$ & $587.8( \pm 16.02)$ \\
orthosis & With orthosis & $9.12( \pm 3.19)$ & $0.4( \pm 0.10)$ & $42.56( \pm 3.16)$ & $28.16( \pm 4.19)$ & $30.99( \pm 3.91)$ & $638( \pm 5.16)$ \\
Carbon & Without orthosis & $9.72( \pm 2.85)$ & $0.46( \pm 0.09)$ & $45.2( \pm 6.28)$ & $33.64( \pm 1.77)$ & $23.1( \pm 4.08)$ & $587.8( \pm 16.02)$ \\
AFO & With orthosis & $8.46( \pm 1.05)$ & $0.4( \pm 0.049)$ & $42.56( \pm 2.32)$ & $36.78( \pm 5.77)$ & $26.28( \pm 1.74)$ & $627.5( \pm 4.04)$ \\
\hline
\end{tabular}

pressure (COP) data collected with the by force plate and kinematics of the joints determined based on the trajectories of the markers during walking. The locations of the center of mass (COM) of the body segments were determined based on Winter approaches ${ }^{7)}$.

Twenty markers (with $14 \mathrm{~mm}$ diameters) were attached bilaterally to the anterior superior iliac spine (ASIS), superior iliac spine (PSIS), medial and lateral malleolus, iliac crests, acromion process, medial and lateral sides of the knee joints, and first and fifth metatarsal heads. Moreover, five marker clusters, each comprising four markers attached on the rhomboid plates, were attached to the anterolateral surface of the leg, thigh, and trunk by use of extensible Velcro straps. The subject was asked to walk along a level surface to collect data from 5 successful trials. The trunk was considered to be the segment between the iliac crest and acromion process. The collected data were filtered with a Butterworth low-pass filter with a cutoff frequency of $100 \mathrm{~Hz}$ and split into phases of the gait cycle using heels strike data. The tests were repeated to collect 5 successful trials and were repeated with and without a posterior leaf spring (PLS) orthosis, a carbon composite AFO, and the external powered AFO. The spatiotemporal gait parameters (stride length, cadence, walking velocity), force applied to the leg, kinematics of the ankle, knee, hip, pelvic, and trunk, and moments applied to the joints were the parameters examined in this study.

\section{RESULTS}

Tables 1 and 2 demonstrate the kinematic and kinetics information obtained during walking under three test conditions for the stroke patient in this study.

The mean of anteroposterior force values were $33.64 \pm 1.77$ and $21.65 \pm 14.51$ during walking without and with Powered AFO, respectively. The magnitude of vertical force applied to the leg was $587.8 \pm 16.02 \mathrm{~N}$ during walking without an orthosis, while it was $774.5 \pm 9.36 \mathrm{~N}$ during walking with the powered AFO. The mean of ankle moment values were $0.6 \pm 0.09 \mathrm{Nm} /$ $\mathrm{BM}$ and $0.739 \pm 0.11 \mathrm{Nm} / \mathrm{BM}$ during walking without and with the powered AFO, respectively. The powered AFO seemed 
Table 2. The gait parameters of the stroke subject during walking without and with three types of orthosis

\begin{tabular}{|c|c|c|c|c|c|c|c|c|c|}
\hline \multirow[b]{2}{*}{$\begin{array}{l}\text { Orthosis } \\
\text { type }\end{array}$} & \multirow[b]{2}{*}{$\begin{array}{l}\text { Test } \\
\text { condition }\end{array}$} & \multicolumn{2}{|c|}{ Ankle joint } & \multicolumn{2}{|c|}{ Knee joint } & \multicolumn{3}{|c|}{ Hip joint } & \multirow{2}{*}{$\begin{array}{c}\text { Pelvic } \\
\text { Range } \\
\text { (degrees) }\end{array}$} \\
\hline & & $\begin{array}{c}\text { Moment } \\
(\mathrm{Nm} / \mathrm{BM})\end{array}$ & $\begin{array}{c}\text { Range } \\
\text { (degrees) }\end{array}$ & $\begin{array}{c}\text { Moment } \\
(\mathrm{Nm} / \mathrm{BM})\end{array}$ & $\begin{array}{c}\text { Range } \\
\text { (degrees) }\end{array}$ & $\begin{array}{c}\text { Flexion } \\
\text { moment } \\
(\mathrm{Nm} / \mathrm{BM})\end{array}$ & $\begin{array}{c}\text { Extension } \\
\text { moment } \\
(\mathrm{Nm} / \mathrm{BM})\end{array}$ & $\begin{array}{c}\text { Range } \\
\text { (degrees) }\end{array}$ & \\
\hline \multirow{2}{*}{$\begin{array}{l}\text { Powered } \\
\text { AFO }\end{array}$} & $\begin{array}{l}\text { Without } \\
\text { orthosis }\end{array}$ & $0.6( \pm 0.09)$ & $22.4( \pm 3.11)$ & $0.133( \pm 0.02)$ & $38.85( \pm 2.49)$ & $0.267( \pm 0.03)$ & $0.554( \pm 0.22)$ & $30.23( \pm 3.9)$ & $15.93( \pm 3.12)$ \\
\hline & $\begin{array}{l}\text { With } \\
\text { orthosis }\end{array}$ & $0.739( \pm 0.11)$ & $24.5( \pm 7.11)$ & $0.228( \pm 0.23)$ & $38.87( \pm 13.6)$ & $0.396( \pm 0.096)$ & $0.624( \pm 0.07)$ & $27.3( \pm 5.90)$ & $25.66( \pm 2.79)$ \\
\hline \multirow{2}{*}{$\begin{array}{l}\text { PLS } \\
\text { orthosis }\end{array}$} & $\begin{array}{l}\text { Without } \\
\text { orthosis }\end{array}$ & $0.6( \pm 0.09)$ & $22.4( \pm 3.11)$ & $0.133( \pm 0.02)$ & $38.85( \pm 2.49)$ & $0.267( \pm 0.03)$ & $0.554( \pm 0.22)$ & $30.23( \pm 3.9)$ & $15.93( \pm 3.12)$ \\
\hline & $\begin{array}{l}\text { With } \\
\text { orthosis }\end{array}$ & $0.687( \pm 0.18)$ & $18.13( \pm 3.58)$ & $0.22( \pm 0.25)$ & $31.97( \pm 12.1)$ & $0.421( \pm 0.025)$ & $0.254( \pm 0.046)$ & $29.58( \pm 3.89)$ & 16.18 \\
\hline \multirow{2}{*}{$\begin{array}{l}\text { Carbon } \\
\text { AFO }\end{array}$} & $\begin{array}{l}\text { Without } \\
\text { orthosis }\end{array}$ & $0.6( \pm 0.09)$ & $22.4( \pm 3.11)$ & $0.133( \pm 0.02)$ & $38.85( \pm 2.49)$ & $0.267( \pm 0.03)$ & $0.554( \pm 0.22)$ & $30.23( \pm 3.9)$ & $15.93( \pm 3.12)$ \\
\hline & $\begin{array}{l}\text { With } \\
\text { orthosis }\end{array}$ & $0.975( \pm 0.04)$ & $21.8( \pm 1.72)$ & $0.146( \pm 0.038)$ & $39.99( \pm 1.35)$ & $0.407( \pm 0.015)$ & $0.286( \pm 0.035)$ & $39.15( \pm 1.75)$ & $27.24( \pm 17.8$ \\
\hline
\end{tabular}

to have no influence on ankle, knee, and hip joint range of motion. An interesting observation was that the stride length of the subject increased but his cadence decreased during walking with the powered AFO. His hip flexion moment values during normal walking and walking with the powered AFO were $0.267 \pm 0.03 \mathrm{Nm} / \mathrm{BM}$ and $0.396 \pm 0.096 \mathrm{Nm} / \mathrm{BM}$, respectively.

There was a difference between the vertical forces applied to the leg during walking without and with the PLS orthosis. The mean ankle moment values during walking with and without the PLS orthosis were the same. Hip joint flexion moment increased during walking with the PLS orthosis. The vertical force applied to the leg during walking with the carbon AFO was $627.5 \pm 4.04 \mathrm{~N}$, which was more than that during normal walking. The ankle moment during walking with the carbon AFO was $0.975 \pm 0.04 \mathrm{Nm} / \mathrm{BM}$, whereas it was $0.6 \pm 0.09 \mathrm{Nm} / \mathrm{BM}$ during normal walking. The subject walked with the carbon AFO with increased range of motion in the hip joint.

\section{DISCUSSION}

This study demonstrated that it is feasible to construct a lightweight powered orthosis providing substantial external torque to the ankle joint for walking in stroke subjects. Unfortunately most previous studies only focused on evaluation of the gait of normal subjects while walking with a powered AFO. The present study evaluated and compared the gait parameters of a stroke patient wearing a powered AFO and traditional AFOs.

The moments of the joints when the subject wore the newly developed orthosis were more than those when he wore no orthosis or the PLS orthosis. This indicates that the new orthosis has greater potential to restore the ability of the subject and to improve gait performance. This may be due to the external power system embedded in the orthosis. The new developed system increased the moment of the ankle joint during push off and also regulated the time of applying moment. Therefore, it can be concluded that it may influence the pattern of walking more than other available orthoses.

It should be noted that the other orthoses, that is, the PLS and carbon orthosis also influenced the gait parameters significantly, but not as much as the newly developed orthosis. The moments produced in knee and hip joints increased significantly more with the new orthosis compared with the other devices. Moreover, the newly developed orthosis has the ability to change the time of applying dorsiflexion and plantar flexion moment. It should also be noted that a robotic orthosis is available that is used mostly while subjects walk on a treadmill to restore the pattern of walking ${ }^{22)}$. The results of the present study suggest that stroke patients could improve their ability to walk and stand in daily activities by walking on a treadmill while wearing the new orthosis 3 to 4 times per week. In future work, we plan to perform a comprehensive biomechanical gait study involving more stroke patients that includes measurement of metabolic, electromyographic, and kinematic and kinetic gait data. Such a biomechanical analysis will provide a quantitative understanding of the effects of orthotics ankle power on stroke ambulation. We also wish to develop additional finite state controllers for other walking modes, such as stair ascent or ramp climbing. Additionally, we hope to further exploit myoelectric signals as control commands to manage switching between finite state controllers appropriate for a large repertoire of locomotory terrains and conditions. It is our hope that this work will motivate additional studies focused on the advancement of multifunctional lower-extremity orthoses.

A limitation of this case study was that the results were only representative of a single subject. A series of walking trials with an appropriate number of stroke subjects would need to be performed to gain further insight into the repeatability of the results. This may be addressed during future development work by reducing the size of the orthosis. Nevertheless, the development team was sufficiently encouraged by the results of this initial testing to confidently continue testing and 
development of the device for use by stroke subjects.

The present study introduced a powered AFO with dorsiflexion and plantar flexion movement enabled with an SEA. The powered AFO employs one actuator component designed to help the kinematic efficiency of level-ground walking when utilizing the orthosis. The ankle joint motor had positive effects on gait parameters (speed, step length) during level-ground walking trials, resulting in observation of an alternative approach to walking in the stroke patient's gait. We hope that this case study will motivate additional research focused on the advancement of powered lower limb orthoses for walking in stroke patients.

\section{REFERENCES}

1) Azarpazhooh MR, Shahripour RB, Kapral MK, et al.: Incidence of first ever stroke during Hajj ceremony. BMC Neurol, 2013, 13: 193. [Medline] [CrossRef]

2) Bjorn-Mortensen K, Lynggaard F, Pedersen ML: Incidence of Greenlandic stroke-survivors in Greenland: a 2-year cross-sectional study. Int J Circumpolar Health, 2013, 72: 22626. [Medline] [CrossRef]

3) Jørgensen HS, Nakayama H, Raaschou HO, et al.: Recovery of walking function in stroke patients: the Copenhagen Stroke Study. Arch Phys Med Rehabil, 1995, 76: 27-32. [Medline] [CrossRef]

4) Danielsson A, Carin W, Katharina S: Comparison of energy cost of walking with and without a carbon composite ankle foot orthosis in stroke subjects. 13th ISPO World Congress; 10-15 May; Leipzig, Germany, 2010

5) Chen G, Patten C, Kothari DH, et al.: Gait differences between individuals with post-stroke hemiparesis and non-disabled controls at matched speeds. Gait Posture, 2005, 22: 51-56. [Medline] [CrossRef]

6) Kadaba MP, Ramakrishnan HK, Wootten ME: Measurement of lower extremity kinematics during level walking. J Orthop Res, 1990, 8: 383-392. [Medline] [CrossRef]

7) Winter DA: The biomechanics and motor control of human gait: normal, elderly and pathological, 2nd ed. Waterloo: Waterloo Biomechanics, 1991.

8) Slijper A, Danielsson A, Willén C: Ambulatory function and perception of confidence in persons with stroke with a custom-made hinged versus a standard ankle foot orthosis. Rehabil Res Pract, 2012, 2012: 206495. [Medline]

9) Pohl M, Mehrholz J: Immediate effects of an individually designed functional ankle-foot orthosis on stance and gait in hemiparetic patients. Clin Rehabil, 2006, 20: 324-330. [Medline] [CrossRef]

10) de Wit DC, Buurke JH, Nijlant JM, et al.: The effect of an ankle-foot orthosis on walking ability in chronic stroke patients: a randomized controlled trial. Clin Rehabil, 2004, 18: 550-557. [Medline] [CrossRef]

11) Blaya JA, Herr H: Adaptive control of a variable-impedance ankle-foot orthosis to assist drop-foot gait. Neural Systems and Rehabilitation Engineering. IEEE Trans, 2004, 12: 24-31.

12) Gök H, Küçükdeveci A, Altinkaynak H, et al.: Effects of ankle-foot orthoses on hemiparetic gait. Clin Rehabil, 2003, 17: 137-139. [Medline] [CrossRef]

13) Ruthenberg BJ, Wasylewski NA, Beard JE: An experimental device for investigating the force and power requirements of a powered gait orthosis. J Rehabil Res Dev, 1997, 34: 203-213. [Medline]

14) Yano H, Kaneko S, Nakazawa K, et al.: A new concept of dynamic orthosis for paraplegia: the weight bearing control (WBC) orthosis. Prosthet Orthot Int, 1997, 21: 222-228. [Medline]

15) Blaya JA, Herr H: Adaptive control of a variable-impedance ankle-foot orthosis to assist drop-foot gait. IEEE Trans Neural Syst Rehabil Eng, 2004, 12: 24-31. [Medline] [CrossRef]

16) Noël M, Cantin B, Lambert S, et al.: An electrohydraulic actuated ankle foot orthosis to generate force fields and to test proprioceptive reflexes during human walking. IEEE Trans Neural Syst Rehabil Eng, 2008, 16: 390-399. [Medline] [CrossRef]

17) Xu R, Jiang N, Mrachacz-Kersting N, et al.: A closed-loop brain-computer interface triggering an active ankle-foot orthosis for inducing cortical neural plasticity. IEEE Trans Biomed Eng, 2014, 61: 2092-2101. [Medline] [CrossRef]

18) Esfahani E: Developing an active ankle foot orthosis based on shape memory alloys University of Toledo, 2007.

19) Yamamoto S, Ibayashi S, Fuchi M, et al.: Immediate-term effects of use of an ankle-foot orthosis with an oil damper on the gait of stroke patients when walking without the device. Prosthet Orthot Int, 2015, 39: 140-149. [Medline] [CrossRef]

20) Ohata K, Yasui T, Tsuboyama T, et al.: Effects of an ankle-foot orthosis with oil damper on muscle activity in adults after stroke. Gait Posture, 2011, 33: 102-107. [Medline] [CrossRef]

21) Yamamoto S, Hagiwara A, Mizobe T, et al.: Development of an ankle-foot orthosis with an oil damper. Prosthet Orthot Int, 2005, 29: 209-219. [Medline] [CrossRef]

22) Popovi'c D: Externally powered and controlled orthotics and prosthetics. The Biomedical Engineering Handbook, 2000.

23) Pratt DJ: Dynamic foot orthoses. Principles and application. J Am Podiatr Med Assoc, 2000, 90: 24-29. [Medline] [CrossRef] 